\title{
Evaluation of the performance of CORDEX regional climate models in simulating present climate conditions of Tanzania
}

\author{
Philbert Luhunga $^{1,2}$ Joel Botai $^{1}$ and Frederick Kahimba ${ }^{3}$ \\ ${ }^{1}$ University of Pretoria, Department of Geography, Geo-Informatics and Meteorology, Pretoria, \\ South Africa \\ ${ }^{2}$ Tanzania Meteorological Agency, Research Section, Dar es Salaam, Tanzania \\ ${ }^{3}$ Sokoine University of Agriculture, Morogoro, Tanzania
}

(Manuscript received September 2015; accepted April 2016)

\begin{abstract}
Regional climate models (RCMs) are widely used in regional assessment of climate change impacts. However, the reliability of individual models needs to be assessed before using their output for impact assessment. In this study, we evaluate the performance of RCMs from the Coordinated Regional Climate Downscaling Experiment program (CORDEX) to simulate minimum air temperature (TN), maximum air temperature (TX) and rainfall over Tanzania. Output from four RCMs driven by boundary conditions from three General Circulation Models (GCMs) and ERA-Interim data are evaluated against observed data from 22 weather stations. The evaluation is based on determining how well the RCMs reproduce climatological trends, interannual, and annual cycles of TN, TX and rainfall. Statistical measures of model performance that include the bias, root mean square error, correlation and trend analysis are used. It is found that RCMs capture the annual cycle of TN, TX and rainfall well, however underestimate and overestimate the amount of rainfall in March-April-May (MAM) and October-November-December (OND) seasons respectively. Most RCMs reproduce interannual variations of TN, TX and rainfall. The source of uncertainties can be analysed when the same RCM is driven by different GCMs and different RCMs driven by same GCM simulate TN, TX and rainfall differently. It is found that the biases and errors from the RCMs and driving GCMs contribute roughly equally. Overall, the evaluation finds reasonable (although variable) model skill in representing mean climate, interannual variability and temperature trends, suggesting the potential use of CORDEX RCMs in simulating $\mathrm{TN}, \mathrm{TX}$ and rainfall over Tanzania.
\end{abstract}

\section{Introduction}

The most advanced tools currently available for simulating the response of the global climate system to increased atmospheric greenhouse gas concentrations are Global Climate Models (GCMs). They describe the relevant physical processes in the atmosphere, oceans, land and ice surfaces that make up the climate system. However, GCMs have relatively coarse space resolution and cannot represent the fine-scale detail that characterises the climate in many regions of the world, especially in regions with complex orography or heterogeneous land surface cover or coastlines. This can makes their climate simulations of limited use in impact studies of climate change on biodiversity, ecosystem services, agricultural systems, species distributions and other landscape and environment related matters (Villegas and Jarvis 2010, Daniels et al. 2012, Hassan et al. 2013, Xiaoduo et al. 2012). These types of impact and adaptation studies require data with much finer spatial resolution. 
One widely applicable method for obtaining high resolution climate information that takes into account regional patterns and valuable local knowledge is to use regional climate models (RCMs). These are atmospheric models run on a limited geographical area using boundary conditions from GCMs (Danis et al. 2002, Min et al. 2013). Their finer spatial resolution allows simulation of local climate conditions in greater detail by incorporation of impacts of orography (mountains, coastlines, water bodies, vegetation) and land-use, and small scale dynamical and boundary layer processes.

In recent years, RCMs have been used extensively to provide climate simulations with high resolution (Xiaoduo et al. 2012, Roux 2009, Wilby and Fowler 2011). These simulations, however, are subject to a number of uncertainties that come from boundary conditions, size of the integration domain, natural variability within the RCMs and RCM formulation (Min et al. 2013). Meier et al. (2011) assessed the impact of boundary conditions from three global climate models (HadCM3, ECHAM4 and ECHAM5) on the Rossby Centre Atmosphere model version 3 (RCA3) RCM in simulating surface meteorological variables over the Baltic Sea. They found that RCA3 simulated annual mean precipitation and the mean seasonal cycle of precipitation much better when driven by ECHAM5 than ECHAM4. Further, they found that ECHAM4 and ECHAM5 driven simulations overestimated both the mean sea level pressure and sea level pressure gradient, while with HadCM3 driven simulations underestimated both of these features. Køltzow et al. (2011) examined the importance of surface forcing and the size of the integration domain for dynamical downscaling with the HIRHAM RCM in simulating the Norwegian climate for the period of 1961-1990 and found that the RCM climate simulations were sensitive to surface forcing as well as the size of the integration domain. Endris et al (2014) evaluated the performance of CORDEX RCMs in simulating East African rainfall during the period of 1990-2008. They found the RCMs simulated rainfall better in one region but more poorly in another region over the same time period. More recently Shongwe et al. (2015) evaluated the performance of CORDEX regional climate model in simulating precipitation over southern Africa. They also found that the performance of the RCMs in simulating precipitation differed over different regions.

A prerequisite before using climate simulation data from the RCMs is evaluation through comparisons of model results with observations. This helps to assess the ability of the RCMs to simulate climate conditions at particular locations. This is important for assessment and the quantification of uncertainties in climate models simulations for use in climate change impact studies and policy decisions at different locations.

A large number of previous studies (e.g. Engelbrecht et al. 2009, Endris et al. 2014) have provided detailed evaluations of the performance of RCMs in simulating southern, eastern and the horn of Africa rainfall and temperature climatology. In these studies, however, the RCMs simulations were evaluated against interpolated gridded data derived from meteorological station measurements. Another recent study is that of Endris et al. (2014), which evaluated the performance of RCMs from CORDEX in simulating east Africa rainfall, where the model outputs were compared with gauge-based gridded observational datasets at $0.5^{\circ}$ by $0.5^{\circ}$ spatial resolution obtained from Global Precipitation Climatology Centre (GPCC), Climate Research Unit (CRU) and Global Precipitation Climatology Project (GPCP).

Although gridded data have shown to be useful for evaluation of RCMs performance, they have a number of potential inaccuracies and errors (Hofstra et al. 2009). These data use interpolation across space and time to combine weather station data into a balanced panel of observations on a fixed spatial scale or grid (Auffhammer et al. 2013). Their quality depends on the number of weather stations used in interpolation processes and the interpolation formula as different schemes produces different estimates, particularly for precipitation (Dell et al. 2014). In developing countries with few weather stations, the quality of gridded data is questionable. For instance, Tanzania has very few weather stations (28-synoptic weather stations) which are sparsely distributed over complex topographical terrain. The use of gridded data to evaluate the performance of RCMs in simulating Tanzania climate may not provide realistic results. Christensen (2001) and Osborn and Hulme (1997) suggested the use of point measurements from weather stations to evaluate grid measurements of the climate model, especially in areas with sparse station networks and complex terrain.

The aim of this study is to evaluate the performance of RCMs from CORDEX in simulating present climate conditions over Tanzania, where actual station observations are used to evaluate the RCMs. This study is a crucial step in choosing reliable models that can be used in climate change impact studies at particular locations. The output from such models will be used in a future study as input into crop models for evaluation of climate change impacts on rain-fed crop production in both current and future climate in Tanzania. This is important since the economy of the country heavily depends on the agriculture sector, which contributes about half of gross production, $30 \%$ of export earnings, $65 \%$ of raw materials for domestic industries and employs about $80 \%$ of the labour force while facing challenges of climate change and variability. Previous studies in Tanzania (Mwandosya et al. 1998, Agrawala et al. 2003, Ernhart and Twena 2006, IPCC 2007, Enfors 
and Gordon, 2008, Thornton et al. 2009, 2010, Arndt et al. 2011, Ahmed et al. 2011, Müller et al. 2011) have evaluated the impact of climate change on rain-fed crop production using climate simulation derived directly from GCMs which are insufficient to detect the huge variations in agricultural output in different regions.

\section{Data and methodology}

\subsection{Study area}

The study area is Tanzania (Figure 1), which is located in east Africa between longitudes $29^{\circ} \mathrm{E}$ to $41^{\circ} \mathrm{E}$ and latitudes $1^{\circ} \mathrm{S}$ and $12^{\circ} \mathrm{S}$. The country has an area of $945000 \mathrm{~km}^{2}$ of which $884000 \mathrm{~km}^{2}$ is land mass and $61000 \mathrm{~km}^{2}$ is lakes, rivers and seashore. Tanzania has complex topography that is very heterogeneous. The height of the topography ranges from sea lev$\mathrm{el}$ in the east to $1600 \mathrm{~m}$ in the west. In the northeastern highlands is the highest mountain in Africa: Mt Kilimanjaro with an altitude of $5895 \mathrm{~m}$, while in the north is the largest lake in Africa: Lake Victoria. In the south are Lake Nyasa and the Ruvuma River, and in the west is the deepest lake in Africa: Lake Tanganyika. Much of the country lies above $1000 \mathrm{~m}$ altitude with many areas over central and northern regions above $1500 \mathrm{~m}$.

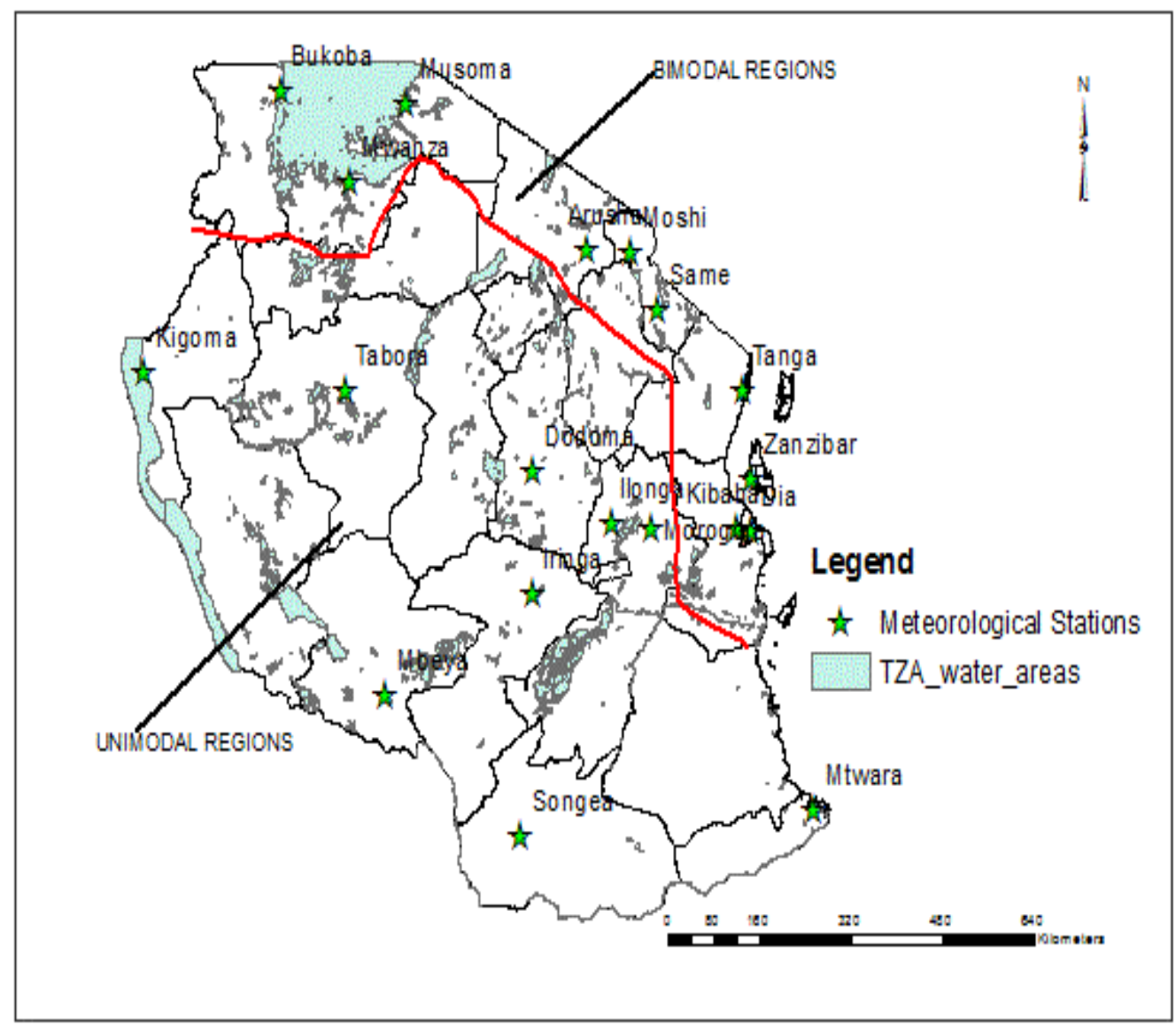

Figure 1 Map of Tanzania showing the location of meteorological stations in unimodal and bimodal regions separated by the red line.

The climate over Tanzania is mainly controlled by the movement of the intertropical convergence zone (ITCZ). However, seasonal interactions within the ITCZ, perturbations in global climate circulation and changes in local circulation systems 
(which are influenced by complex topographical features) all contribute to high local climate variability. The seasonal rainfall is modulated by changes in the global sea surface temperatures (SSTs) especially over the equatorial Pacific and Indian oceans (Black et al. 2003, Black 2005, Anyah and Semazzi 2007).

Tanzania is characterised by two rainfall seasons, namely March-April-May (MAM) and October-November-December (OND). These seasons are mainly driven by the migration of the ITCZ, which lags behind the overhead sun by 3-4 weeks over the region (Owiti and Zhu 2012). The ITCZ migrates towards southern regions of Tanzania in October-December, reaching southern parts of the country in January-February and reverses northwards in March, April and May (Timiza 2011). Due to this movement, some areas experience single and double passages of the ITCZ (Owiti and Zhu 2012). Regions with a single passage are known as unimodal areas (see Figure 1) and include the southern, southwestern, central and western parts of the country which receive rainfall from October through to April or May (Timiza 2011). Areas that experience a double passage are known as bimodal areas, and include north, northern coast, northeastern highlands, the Lake Victoria basin and the islands of Zanzibar (Unguja and Pemba). These regions receive two distinct rainfall seasons: the long rain season (known as Masika in Swahili) which starts in March and continues through May (MAM); and the short rainfall season (Vuli in Swahili) which starts in October and continues through December (OND) (Agrawala et al. 2003).

As reported in Zorita and Tillya (2002) and Camberlin et al. (2009), the amount of seasonal rainfall varies significantly in space and time, with higher variation observed during the Vuli season than in Masika. The rainfall falling in these seasons usually ranges from 50-200 mm per month but varies greatly between regions and can be as much as $300 \mathrm{~mm}$ per month in wettest regions and seasons (McSweeney et al. 2010). Higher amounts of seasonal rainfall are recorded over the southwestern and northeastern highlands, while central Tanzania is semi-arid, receiving seasonal rainfall of less than $50 \mathrm{~mm}$ per month. Annual average rainfall over Tanzania ranges from $534 \mathrm{~mm}$ to $1837 \mathrm{~mm}$.

\begin{tabular}{|c|c|c|c|c|}
\hline No. & $R C M$ & Model centre & $\begin{array}{l}\text { Short name } \\
\text { of } R C M\end{array}$ & $G C M$ \\
\hline 1 & $\begin{array}{l}\text { CLMcom COSMO- } \\
\text { CLM } \\
\text { (CCLM4) }\end{array}$ & $\begin{array}{l}\text { Climate Limited-Area } \\
\text { Modelling (CLM) } \\
\text { Community }\end{array}$ & CCLM4 & $\begin{array}{l}\text { MPI } \\
\text { ICHEC } \\
\text { CNRM }\end{array}$ \\
\hline 2 & DMI HIRHAM5 & $\begin{array}{l}\text { Danmarks } \\
\text { Meteorologiske } \\
\text { Institut (DMI), } \\
\text { Danmark }\end{array}$ & HIRHAM5 & ICHEC \\
\hline 3 & $\begin{array}{l}\text { SMHI Rossby } \\
\text { Center Regional } \\
\text { Atmospheric } \\
\text { Model (RCA4) }\end{array}$ & $\begin{array}{l}\text { Sveriges } \\
\text { Meteorologiska } \\
\text { och Hydrologiska } \\
\text { Institut (SMHI), } \\
\text { Sweden }\end{array}$ & RCA4 & $\begin{array}{l}\text { MPI } \\
\text { ICHEC } \\
\text { CNRM }\end{array}$ \\
\hline 4 & $\begin{array}{l}\text { KNMI Regional } \\
\text { Atmospheric Climate } \\
\text { Model, version } 2.2 \\
\text { (RACMO2.2T) }\end{array}$ & $\begin{array}{l}\text { Koninklijk } \\
\text { Nederlands } \\
\text { Meteorologisch } \\
\text { Instituut (KNMI), } \\
\text { Netherlands }\end{array}$ & RACMO22T & ICHEC \\
\hline
\end{tabular}

Table 1 Details of CORDEX-RCMs and the driving GCMs. 
The annual average temperature over different stations in Tanzania ranges from $14.4-26.4{ }^{\circ} \mathrm{C}$. Regions with the highest temperatures are along the coast and western parts of the country. The season with high temperatures starts from October, continuing through February or March, whilst the cold season is from May to August. The annual minimum air temperature (TN) and maximum air temperature (TX) across the stations in Tanzania ranges from $9.6-22{ }^{\circ} \mathrm{C}$ and $19.1-30.7{ }^{\circ} \mathrm{C}$ respectively.

\section{Data}

\subsection{Model data}

The CORDEX program archives outputs from a set of RCM simulations over different regions in the world. The CORDEX domains for model integrations are found at http://wcrp-cordex.ipsl.jussieu.fr/images/pdf/cordex_regions.pdf. In this study datasets from CORDEX Africa are accessed from http://cordexesg.dmi.dk/esgf-web-fe/. The datasets are quality controlled and may be used according to the terms of use (http://wcrp-cordex.ipsl.jussieu.fr/). The spatial grid resolutions of all CORDEX Africa RCMs were set to longitude $0.44^{\circ}$ and latitude $0.44^{\circ}$ using a rotated pole system coordinate. These models operate over an equatorial domain with a quasi-uniform resolution of approximately $50 \mathrm{~km}$ by $50 \mathrm{~km}$. For detailed description of CORDEX RCMs and their dynamics and physical parameterisation consult Nikulin et al. (2012). Table 1 lists the details of CORDEX-RCMs and the driving GCMs: CNRM-CERFACS-CNRM-CM5 (CNRM), ICHECEC-EARTH (ICHEC) and MPI-M-MPI-ESM-LR (MPI)

Output from CORDEX-RCMs driven by boundary conditions from the GCMs for the period 1971-2005 are used to assess the ability of the RCMs to simulate annual cycles of TN and TX and rainfall. The ERA-Interim driven simulations which are available for the period 1989-2008 are used to assess the ability of CORDEX RCMs to simulate interannual variability and trends in TN, TX and rainfall.

\subsection{Observed data}

Monthly mean TN, TX and rainfall for the period 1971-2005 from 22 weather stations are obtained from the Tanzania Meteorological Agency (TMA). Table 2 indicates the geographical information of weather stations managed by TMA with their long term annual statistical moments of observed TN, TX and rainfall.

\section{Analysis method}

\subsection{Interpolation of gridded climate data from the RCMs}

The RCMs simulate different climate variables such as TN, TX and rainfall at each grid point. The quality of their output can be evaluated against actual measurements from weather stations using several techniques. One of the methods is to interpolate gridded climate variables to the location of weather stations and compare the results with observed station data. There are different interpolation methods (Ly et al. 2013); the simplest is to calculate the arithmetic mean of climate variables from the nearest four grid points around the station. This method assigns equal weights from four grids in estimating climate variable at the station, and may not give realistic estimates of climate variables such as rainfall which have strong spatial variability.

Another interpolation method is the nearest neighbour method, which assumes that climate simulation at a given weather station is equal to that at the closest grid point. This method considers discrete values and does not consider spatial variation of climate variable between four grids surrounding the station (Hartkamp et al. 1999). Therefore, the use of nearest neighbour to interpolate climate variables with strong spatial variation such as rainfall could lead to erroneous results. 


\begin{tabular}{|c|c|c|c|c|c|c|c|c|c|c|}
\hline$I D$ & $\begin{array}{l}\text { Station } \\
\text { Name }\end{array}$ & $\begin{array}{l}\text { Latitude } \\
\left({ }^{\circ} S\right)\end{array}$ & $\begin{array}{l}\text { Longitude } \\
\left({ }^{\circ} E\right)\end{array}$ & $\begin{array}{l}\text { Alt } \\
(m)\end{array}$ & $\begin{array}{l}T N \\
\left({ }^{\circ} \mathrm{C}\right)\end{array}$ & $\begin{array}{l}S D V \\
\left({ }^{\circ} \mathrm{C}\right)\end{array}$ & $\begin{array}{l}T X \\
\left({ }^{\circ} \mathrm{C}\right)\end{array}$ & $\begin{array}{l}S D V \\
\left({ }^{\circ} \mathrm{C}\right)\end{array}$ & $\begin{array}{l}\text { Rainfall } \\
(\mathrm{mm})\end{array}$ & $\begin{array}{l}S D V \\
(\mathrm{~mm})\end{array}$ \\
\hline 1 & Songea & 10.41 & 35.35 & 1067 & 15.7 & 0.4 & 26.9 & 0.4 & 1098.7 & 203.1 \\
\hline 2 & Mtwara & 10.21 & 40.11 & 113 & 20.9 & 0.4 & 30.1 & 0.3 & 1089.8 & 208.5 \\
\hline 3 & Bukoba & 1.2 & 31.49 & 1144 & 16.7 & 0.7 & 25.8 & 0.3 & 1836.8 & 447.7 \\
\hline 4 & Musoma & 1.3 & 33.48 & 1147 & 17.5 & 0.6 & 28.5 & 0.5 & 867.5 & 176.7 \\
\hline 5 & Mwanza & 2.28 & 32.55 & 1140 & 17.4 & 0.9 & 28.1 & 0.5 & 1051.1 & 215.8 \\
\hline 6 & Arusha & 3.2 & 36.37 & 1387 & 14.2 & 0.4 & 25.8 & 0.5 & 810.1 & 271.2 \\
\hline 7 & Moshi & 3.21 & 37.2 & 813 & 17.8 & 0.4 & 29.4 & 0.4 & 893.8 & 250.3 \\
\hline 8 & $\begin{array}{l}\text { Kilimanja- } \\
\text { ro }\end{array}$ & 3.25 & 37.04 & 896 & 17.2 & 0.5 & 29.8 & 0.5 & 534.1 & 199.4 \\
\hline 9 & Kigoma & 4.53 & 29.4 & 820 & 18.7 & 0.4 & 28.5 & 0.6 & 991.9 & 138.6 \\
\hline 10 & Same & 0.5 & 37.43 & 860 & 17.6 & 0.6 & 29.0 & 0.4 & 561.5 & 200.2 \\
\hline 11 & Tabora & 5.05 & 32.5 & 1182 & 16.9 & 0.5 & 29.6 & 0.8 & 949.2 & 170.4 \\
\hline 12 & Tanga & 5.05 & 39.04 & 49 & 22.0 & 0.5 & 30.7 & 0.3 & 1325.4 & 325.4 \\
\hline 13 & Dodoma & 6.1 & 35.46 & 1120 & 16.8 & 0.3 & 28.9 & 0.4 & 577.6 & 116.0 \\
\hline 14 & Ilonga & 6.46 & 37.02 & 503 & 19.3 & 0.7 & 30.4 & 0.4 & 1053.3 & 197.0 \\
\hline 15 & Morogoro & 6.5 & 37.39 & 526 & 18.9 & 0.5 & 30.2 & 0.4 & 847.9 & 166.9 \\
\hline 16 & Kibaha & 6.5 & 38.38 & 167 & 20.7 & 0.8 & 30.3 & 0.4 & 983.1 & 218.8 \\
\hline 17 & Zanzibar & 6.13 & 39.13 & 18 & 22.0 & 0.7 & 30.5 & 0.3 & 1713.4 & 392.7 \\
\hline 18 & $\begin{array}{l}\text { DaresSa- } \\
\text { laam }\end{array}$ & 6.53 & 39.12 & 53 & 20.9 & 0.5 & 30.7 & 0.4 & 1146.8 & 228.3 \\
\hline 19 & Iringa & 7.4 & 35.45 & 1428 & 14.5 & 0.5 & 26.4 & 0.4 & 598.1 & 88.1 \\
\hline 20 & Mbeya & 8.56 & 33.28 & 1758 & 10.8 & 0.8 & 23.8 & 0.4 & 925.6 & 150.4 \\
\hline 21 & Mlingano & 8.09 & 38.54 & 183 & 20.4 & 1.2 & 30.6 & 0.6 & 1145.1 & 295.7 \\
\hline 22 & Igeri & 9.4 & 34.4 & 2250 & 9.6 & 0.6 & 19.1 & 0.5 & 1337.6 & 202.7 \\
\hline
\end{tabular}

Table 2 Geographic information of weather stations managed by TMA with the long term (1971-2000) annual statistical moments of observed TN, TX and rainfall and their interannual standard deviations (SDV).

The Inverse Distance Weighted Average interpolation method (IDWA) is the estimation method whereby a climate variable at a weather station is estimated by a linear combination of the simulated climate variable at the surrounding grid points (Hartkamp et al. 1999, Ly et al. 2013). This method is defined mathematically as:

$$
\bar{V}_{f}=\frac{\sum_{i=1}^{n} \frac{1}{d_{i}^{2}} V_{i}}{\sum_{i=1}^{n} \frac{1}{d_{i}^{2}}}
$$


where, $\bar{V}_{f}$ is the interpolated value at the required station, $V_{i}$ is data at grid point $i, d_{i}$ is the distance from grid point $i$ to the station, $n$ is the total number of grid points surrounding the station (which is always 4) and $\frac{1}{d_{i}{ }^{2}}$ is the weight of the distance from the grid point to station. The weighting of the grids is strictly a function of the distance from the station. This method was tested by Hartkamp et al. (1999) and yielded best results for interpolation of precipitation in comparison to other techniques.

In this study, IDWA is used to interpolate model gridded climate simulations to the location of weather stations. The distance from the grid point to the station is computed using the Haversine formula (Ingole and Nichat 2013). This formula has been widely applied (e.g. Essayad 2011, Chopde and Nichat 2013) to compute the shortest distance between two points on the earth's surface. The Haversine formula is defined as:

$$
d=2 r \sin ^{-1}\left(\sqrt{\sin ^{2}\left(\frac{\phi_{2}-\phi_{1}}{2}\right)+\cos \phi_{1} \cos \phi_{2} \sin ^{2}\left(\frac{\psi_{2}-\psi_{1}}{2}\right)}\right)
$$

where $d$ is the distance between two points on the earth's surface, $r$ is the earth's radius, $\psi$ is the longitude and $\phi$ is latitude.

\subsection{Criteria for evaluating the performance of regional climate models (RCMs)}

The ability of RCMs to simulate climate conditions at a particular location can be evaluated using a variety of techniques (Flato et al. 2013). However, no individual evaluation technique or performance measure is considered superior; rather, it is combined use of many techniques and measures that provides a comprehensive overview of model performance (Flato et al. 2013). In this study, outputs from RCMs are evaluated against observations using some of the statistical measures recommended by the World Meteorological Organization (WMO) as reported in Gordon and Shaykewich (2000). These statistics include bias, root mean square error and Pearson correlation coefficient given in Eqns 3, 4 and 5.

$$
\begin{gathered}
\text { Bias }=\frac{1}{N} \sum_{i=1}^{N}\left(F_{i}-O_{i}\right) \\
R M S E=\sqrt{\frac{1}{N} \sum_{i=1}^{N}\left(F_{i}-O_{i}\right)^{2}} \\
r_{(F, O)}=\frac{\sum_{i=1}^{N}\left(F_{i}-\bar{F}\right)\left(O_{i}-\bar{O}\right)}{\sqrt{\sum_{i=1}^{N}\left(O_{i}-\bar{O}\right)^{2}} \sqrt{\sum_{i=0}^{N}\left(F_{i}-\bar{F}\right)^{2}}}
\end{gathered}
$$

where $F$ and $O$ are the simulated and observed values respectively, while $i$ refers to the simulated and observed pairs and $N$ is the total number of such pairs. For rainfall analysis and for simple interpretation, normalised versions of Eqn 3 and 4 , that is normalised bias (hereafter NBias) and normalized root mean square error (NRMSE) given in Eqn 6 and 7 respectively are also used.

$$
\begin{aligned}
& \text { NBias }=\frac{\text { Bias }}{M E A N_{O b s}} \times 100 \\
& N R M S E=\frac{R M S E}{M E A N_{O b S}} \times 100
\end{aligned}
$$

The NBias is a percentage measure of whether RCMs overall underestimate or overestimate a particular climate variable. Positive NBias values indicate overestimation while negative values indicate underestimation by the climate model. On the other hand, the NRMSE is a measure of the absolute error of climate model in simulating certain climate variable. The smaller the NRMSE the better the model and vice versa. The Pearson correlation coefficient is a measure of strength of relationship between model simulations and observations and has the limits of 1 and -1 . A Pearson correlation coefficient of 1 indicates a perfect positive correlation between model and observed data, while -1 indicates a perfect negative correlation between the two. In this study the Pearson correlation coefficient is calculated using Eqn 5 where observed average annual cycles over the full period (1971-2005) from different stations are compared with the output from the RCMs (i.e. annual cycles of the 35 year averaged months).

The long term (1971-2005) annual cycle of TN and TX for Tanzania, calculated as the arithmetic mean of all 22 weather stations, is compared with the outputs from the RCMs to determine how well the RCMs driven by GCMs capture the TN 
and TX seasonality. Moreover, the annual cycles of rainfall in bimodal and unimodal regions, calculated as the arithmetic mean of all 14 stations in the bimodal and 8 stations in the unimodal regions, are evaluated against output from RCMs driven by ERA-Interim data, which are available for the period 1989-2008 to assess how well the RCMs capture rainfall interannual variability these two distinct regions of Tanzania.

Mann-Kendall (MK) and Theil-SEN slope estimator methods are used to test the ability of the RCMs driven by ERAInterim data to simulate trends and the magnitude of the trends in interannual series of TN and TX. All trends are computed at station level for the period 1989-2008. Mann-Kendall (MK) and Theil-SEN slope estimators are widely used for trends tests as well as estimation of magnitude of the trends in climatological time series. For detailed descriptions of mathematical formula and the applications of Mann-Kendall (MK) and Theil-SEN's slope estimator statistics the reader may consult Ahmad et al. (2015).

\section{Results}

\subsection{Spatial distribution of biases and root mean square error}

The biases and root mean square error calculated using Eqns 3 and 4 are used to assess how well the RCMs can simulate long term (1971-2005) TN and TX over different stations, while the normalised bias (NBias) and root mean square error (NRMSE) calculated using Eqns 6 and 7 are used to assess how well the RCMs can simulate long term (1971-2005) rainfall over different stations. Figure 2 presents the biases in TN at different stations. From this figure RACMO22T driven by ICHEC underestimates TN by $-2{ }^{\circ} \mathrm{C}$ to zero over central, parts of the northeastern highlands, northern, northern coast and western regions. It simulates TN with biases in the range of -4 to $-2{ }^{\circ} \mathrm{C}$ over Same, Morogoro, Tabora, Iringa, and Songea. This model simulates TN with coldest biases in the range of -5 to $-4{ }^{\circ} \mathrm{C}$ over Moshi and Ulanga (Ilonga) regions. Warm biases of zero to $2{ }^{\circ} \mathrm{C}$ are simulated over coastal regions and over southwestern highlands. HIRHAM5 driven by ICHEC overestimates TN by zero to $2{ }^{\circ} \mathrm{C}$ over central, parts of northeastern highlands, Morogoro, Iringa, Tabora and over northern coast regions, and by 2 to $4{ }^{\circ} \mathrm{C}$ over western, southern, southwestern highlands, coastal and northern regions. It simulates TN with cold biases in the range of $-2^{\circ} \mathrm{C}$ to zero over Moshi and Ulanga (Ilonga) regions.

Figure 2 allows the characterising of RCM uncertainty arising from their formulations and driving GCMs. The uncertainty due to RCM formulations is noticeable in Figure 2, where RACMO22T and HIRHAM5, both driven by ICHEC GCM, simulate TN with different level of performance over all stations. The former underestimates TN over most stations while the later overestimates TN over most stations. However, both RACMO22T and HIRHAM5 simulate TN over Moshi and Ulanga (Ilonga) regions with cold biases in the range of -5 to $-4{ }^{\circ} \mathrm{C}$ and $-2^{\circ} \mathrm{C}$ to zero, respectively. Moreover, both RACMO22T and HIRHAM5 simulate TN over Mbeya region with warm biases in the range of zero to $2{ }^{\circ} \mathrm{C}$ and 2 to $4{ }^{\circ} \mathrm{C}$ respectively.

The uncertainties of RCMs in simulating TN that arises from the driving GCM can also be characterised from Figure 2. This figure shows that CCLM4 driven by three GCMs (MPI, ICHEC and CNRM), simulate TN differently. CCLM4 simulate TN over northern, western, southwestern highlands, and coastal regions with warm biases in the range of zero to $2{ }^{\circ} \mathrm{C}$ and 2 to $4{ }^{\circ} \mathrm{C}$ when is driven by CNRM, and MPI. TN over Moshi and Ulanga (Ilonga) regions is underestimated in the range of -4 to $-2{ }^{\circ} \mathrm{C}$ by CNRM, ICHEC and MPI driven simulations. The TN over Mbeya region is overestimated in the range of zero to $2{ }^{\circ} \mathrm{C}$, and 2 to $4{ }^{\circ} \mathrm{C}$ when CCLM4 driven by ICHEC and CNRM or MPI respectively. These biases seem to be insensitive to the choice of the GCM. Generally, CCLM4 driven by all three GCMs simulate TN over most stations better compared to RACMO22T and HIRHAM5.

RCA4 shows small sensitivity to the driving GCM (Figure 2). RCA4 driven by three GCMs (ICHEC, MPI and CNRM) underestimate $\mathrm{TN}$ over most regions. This model driven by all GCMs overestimates $\mathrm{TN}$ in the range of zero to $2{ }^{\circ} \mathrm{C}$ over southwestern highlands and coastal regions. RCA4 driven by all three GCMs (CNRM, ICHEC and MPI) simulate TN over western, northern, parts of northeastern highlands, central and southern regions with biases in the range of $-2{ }^{\circ} \mathrm{C}$ to zero. In general RCA4 driven by three GCMs simulate TN over most stations better compared to other RCMs, particularly over the coastal region suggesting its potential use in simulating TN over most regions.

Analysis of the performance of RCMs in simulating TX at different stations is presented in Figure 3. All RCMs underestimate TX over most regions. RACMO22T driven by ICHEC simulates TX over southwestern and parts of northeastern highlands with the biases in the range of -1 to $1^{\circ} \mathrm{C}$. This model simulates TX over western, southern and eastern parts of Lake Victoria and Ilonga region with biases in the range -7 to $-5^{\circ} \mathrm{C}$. 

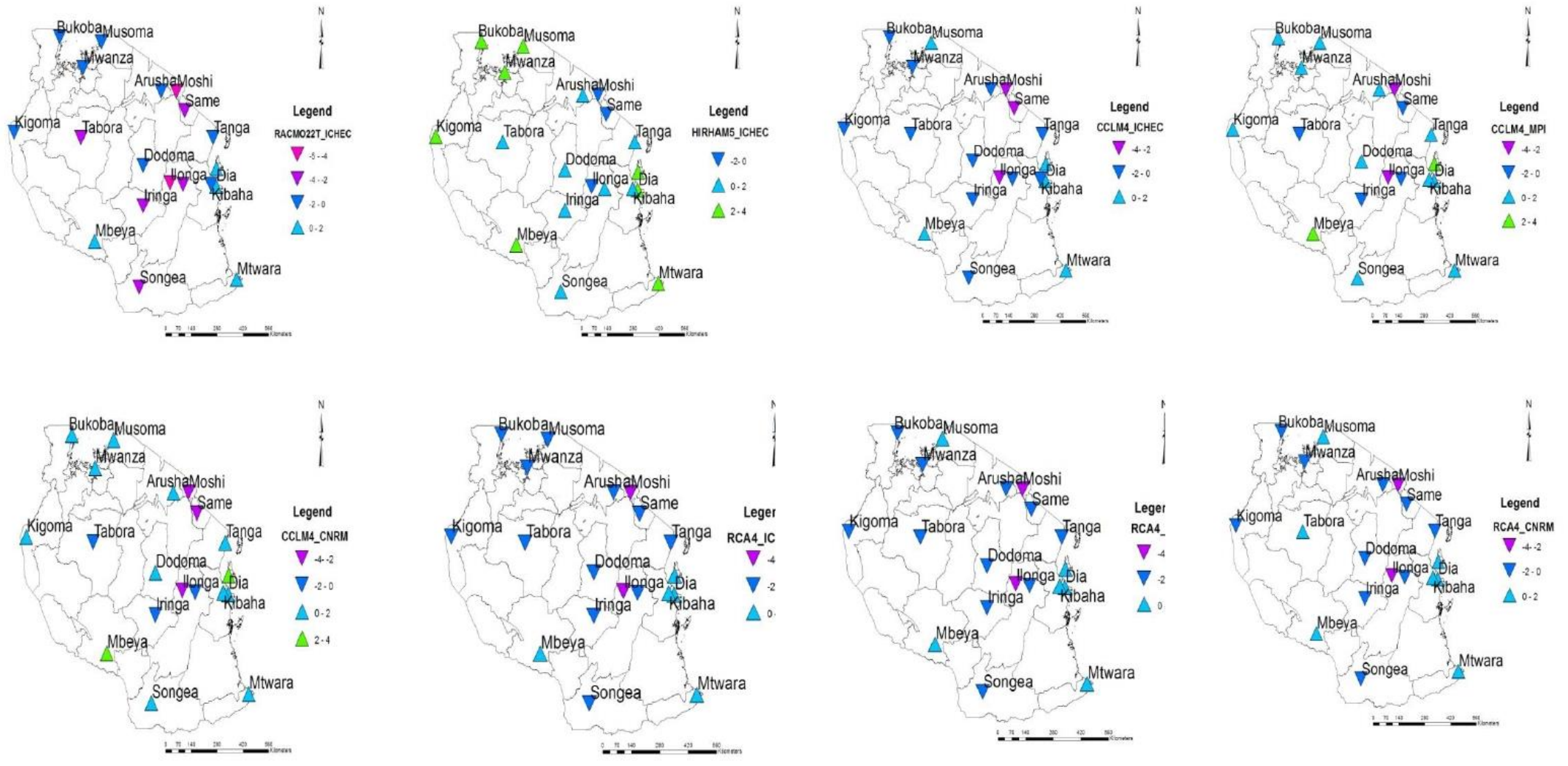

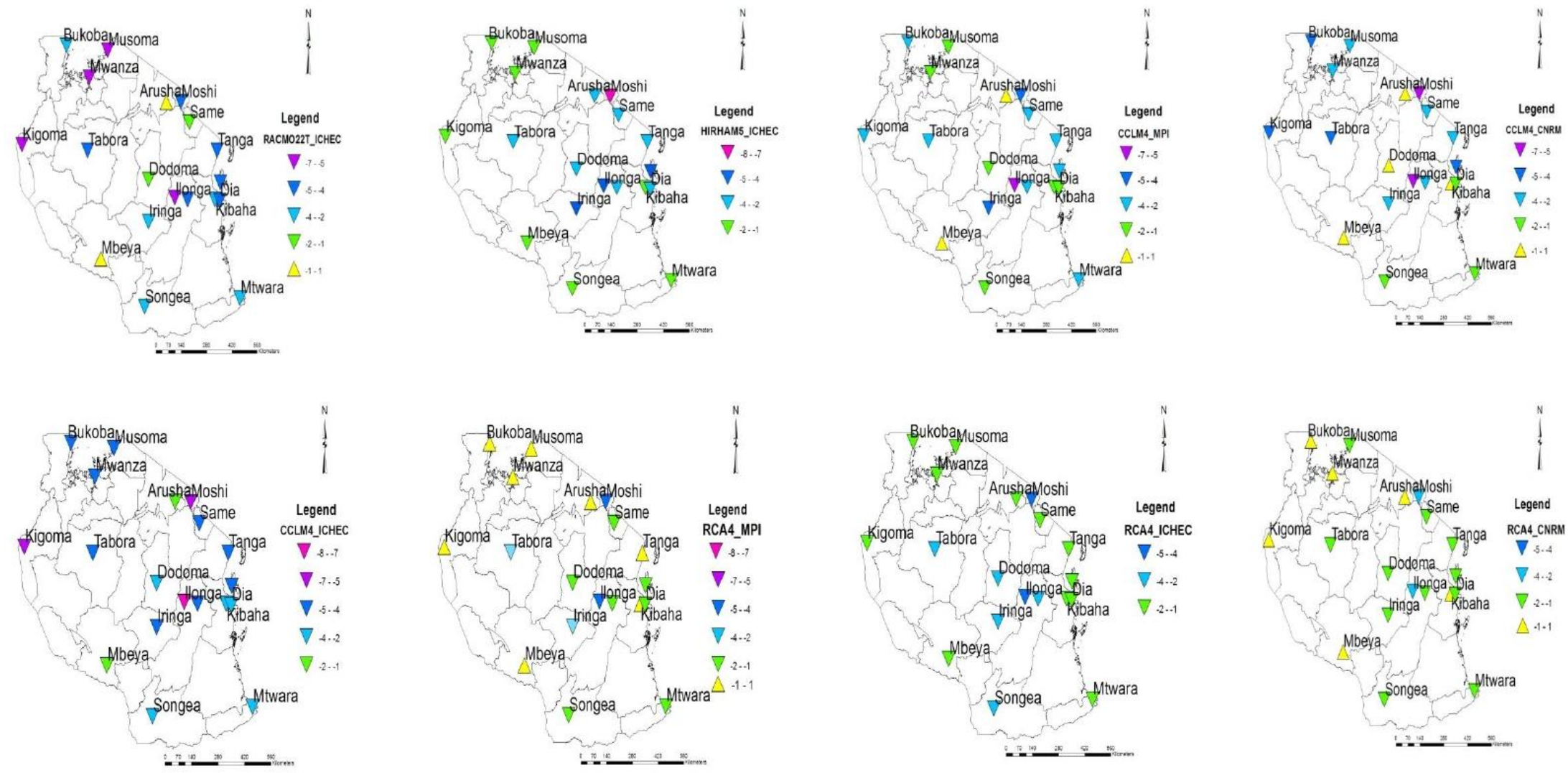

Figure 3 Bias of the RCMs $\left({ }^{\circ} \mathrm{C}\right)$ in simulating maximum temperature at different stations in Tanzania 
RACMO22T and HIRHAM5 both driven by ICHEC simulate TX differently over most stations. TX over central and parts of northeastern highland is underestimated in the range of -2 to $-1{ }^{\circ} \mathrm{C}$, and -4 to $-2{ }^{\circ} \mathrm{C}$ by $\mathrm{RAC}$ MO22T and HIRHAM5 respectively. The impact of driving GCMs on RCM to simulate TX can be characterised from Figure 3. This figure shows that CCLM4 driven by three GCMs (MPI, ICHEC and CNRM) simulate TX differently over most stations. CCLM4 simulate TX over Mbeya and Arusha with biases in the range of -2 to $-1{ }^{\circ} \mathrm{C}$ and -1 to $-1{ }^{\circ} \mathrm{C}$ when driven by ICHEC and CNRM or MPI respectively. TX over the eastern side of Lake Victoria is underestimated in the range of -5 to $-4{ }^{\circ} \mathrm{C},-4$ to $-2{ }^{\circ} \mathrm{C}$, and -2 to $-1{ }^{\circ} \mathrm{C}$ when CCLM4 is driven by ICHEC, CNRM and IMP respectively. These biases seems to be insensitive to the choice of the GCM, thus CCLM4 driven by any of the three GCMs can be used to simulate TX over Mbeya and Arusha regions.

RCA4 driven by three GCMs (MPI, ICHEC and CNRM) simulates TX over most stations better than other models. RCA4 driven by CNRM simulates TX over southwestern highland, western, parts of northern, northeastern highlands and coastal regions with biases in the range of -1 to $1{ }^{\circ} \mathrm{C}$. Generally the biases from all GCMs are not large suggesting that RCA4 driven by all three GCMs can be used to simulate TX over most regions in Tanzania. In general, the biases that arise from the RCMs and driving GCMs in simulating TN and TX are roughly equal in most stations. The RCMs simulate TN better than TX in most stations. TX is underestimated almost in all stations.

The performance of RCMs in simulating rainfall over different stations is presented in Figure 4. This figure shows that RACMO22T and HIRHAM5 both driven by ICHEC simulate rainfall differently over most stations. RACMO22T overestimate rainfall over southern, southern coast and parts of central regions with biases in the range of 8 to $24 \%$. HIRHAM5 also overestimates rainfall over the same regions with biases in the range of -3 to $+45 \%$. In general RACMO2T driven by ICHEC simulates rainfall over most stations in unimodal and bimodal region better than other models.

The RMSE of RCMs in simulating TN over different stations is presented in Figure 5. This figure shows that RACMO22T driven by ICHEC simulates TN over Arusha, Mbeya, coastal and Musoma regions with an error in the range of 0 to $1{ }^{\circ} \mathrm{C}$. The model simulates $\mathrm{TN}$ over Moshi and Ilonga regions with relatively large error in the range of 4 to $5{ }^{\circ} \mathrm{C}$. It simulates TN over western, central, southern and western parts of Lake Victoria with an error in the range of 1 to $2{ }^{\circ} \mathrm{C}$. HIRHAM5 driven by ICHEC simulate TN over central, parts of the southwestern highlands, Morogoro and Same regions with an error in the range of zero to $1{ }^{\circ} \mathrm{C}$. This model simulates TN over Musoma and parts of southwestern highlands with a relatively large error in the range of 4 to $5{ }^{\circ} \mathrm{C}$. In general RACMO22T and HIRHAM5 simulate TN with different level of performance. The former simulates TN with small error over the coastal regions and southwestern highlands, while the later simulates TN with small error over central regions. RACMO22T simulates TN with small error in the range of zero to $1{ }^{\circ} \mathrm{C}$ over Musoma and southwestern highlands, while HIRHAM5 TN over the same regions with relatively large error in the range of 4 to $5^{\circ} \mathrm{C}$.

CCLM4 simulates TN over most stations with an error in the range of zero to $1{ }^{\circ} \mathrm{C}$ when is driven by three GCMs (MPI, CNRM and ICHEC). Generally the model simulates TN in an almost similar way when driven by all three GCMs. This indicates that the error from the driving GCMs in simulating TN over different regions are almost equal and therefore any of the three driving GCM can be used to simulate TN over different regions in Tanzania. However, the model simulates TN over Moshi and Ilonga regions with relatively large error in the range of 3 to 4 ${ }^{\circ} \mathrm{C}$. Like CCLM4, RCA4 driven by MPI, CNRM and ICHEC simulate TN over most stations with an error in the range of zero to $1{ }^{\circ} \mathrm{C}$. Generally RCA4 simulate $\mathrm{TN}$ over most stations better compared to other models irrespective to the driving GCMs. Although RCA4 is slightly better, all models show reasonably comparable errors. In general all models are acceptable to be used to simulate TN over most stations in Tanzania.

The RMSE of RCMs in simulating TX over different stations are presented in Figure 6. RACMO22T and HIRHAM5 both driven by ICHEC simulate TX over most stations differently. TX over Musoma and Kigoma is simulated by RACMO22T and HIRHAM5 with an error in the range of 5 to $6{ }^{\circ} \mathrm{C}$ and 2 to $3{ }^{\circ} \mathrm{C}$ respectively. RACMO22T simulates TX poorly over Mwanza and Ilonga, while HIRHAM5 performs poorly over the Moshi region. Generally CCLM4 driven by all three GCMs simulate TX over north and southern regions with error in the range of 1 to $4{ }^{\circ} \mathrm{C}$. RCA4 driven by MPI and CNRM simulate TX over all stations with similar level of performance. Generally RCA4 driven by all three GCMs simulate TX over different regions better compared with other RCMs irrespective to the driving GCMs. Although RCA4 simulates TX slightly better, all models show generally comparable error in simulating TX over most stations in Tanzania. 

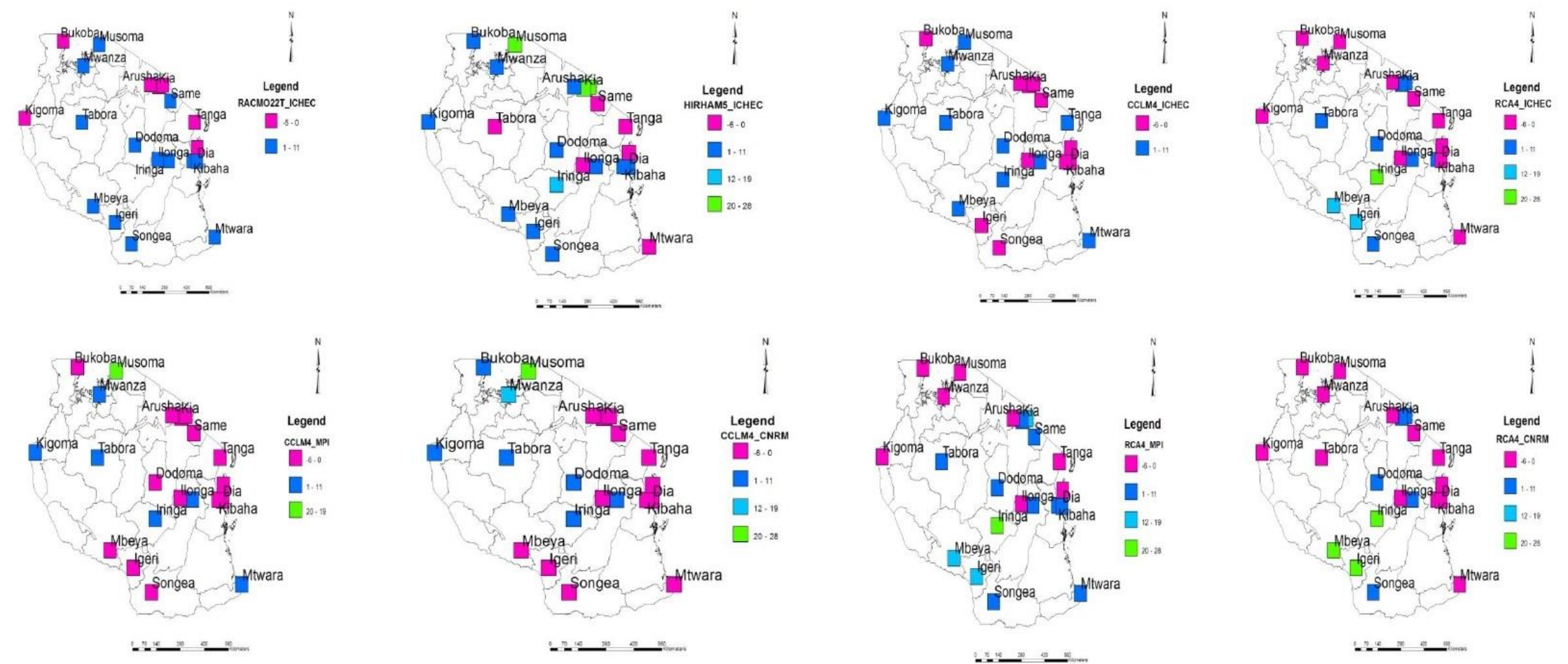

Figure 4 NBias (\%) of the RCMs in simulating rainfall at different stations in Tanzania (note that the scales are different for each model). 

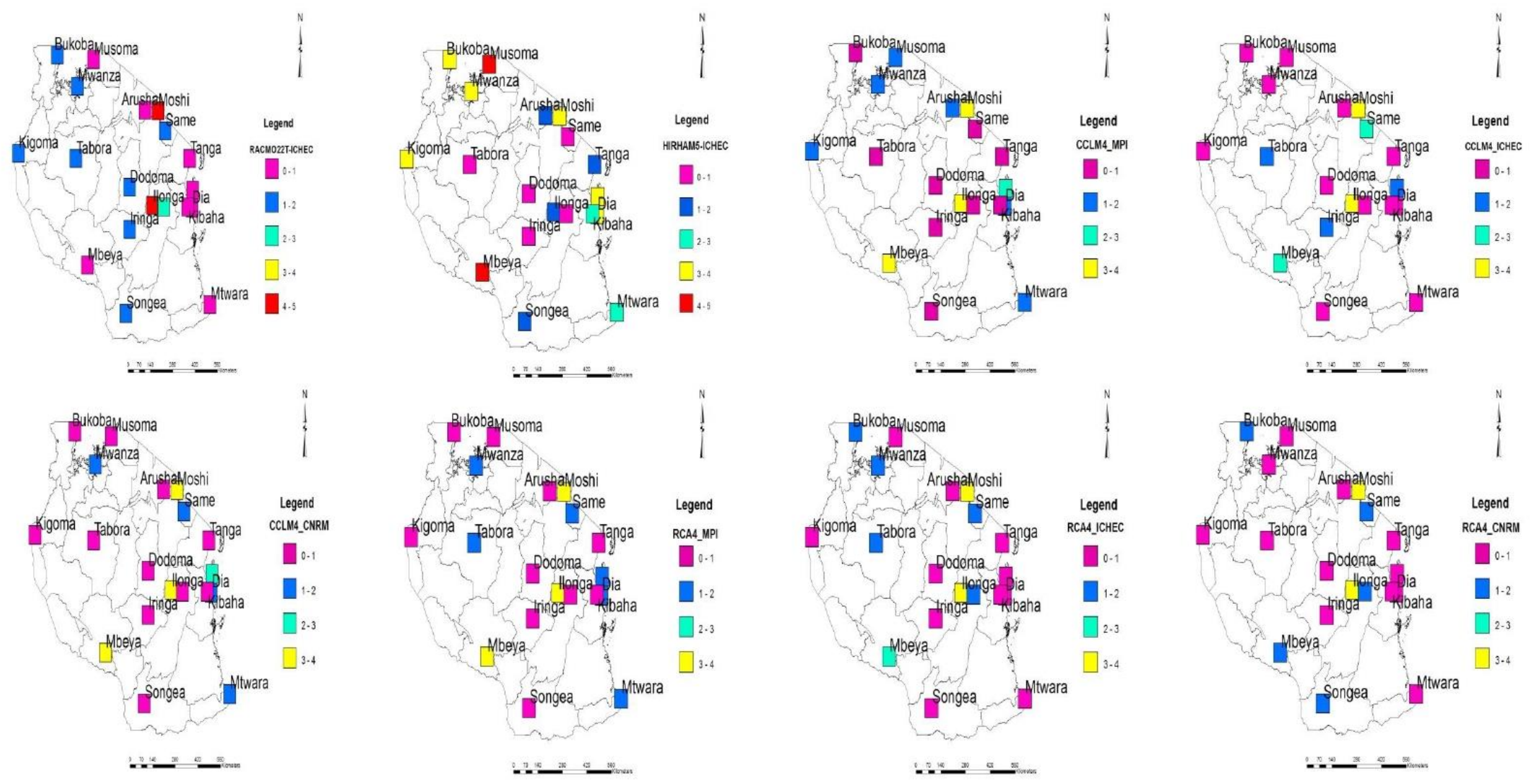

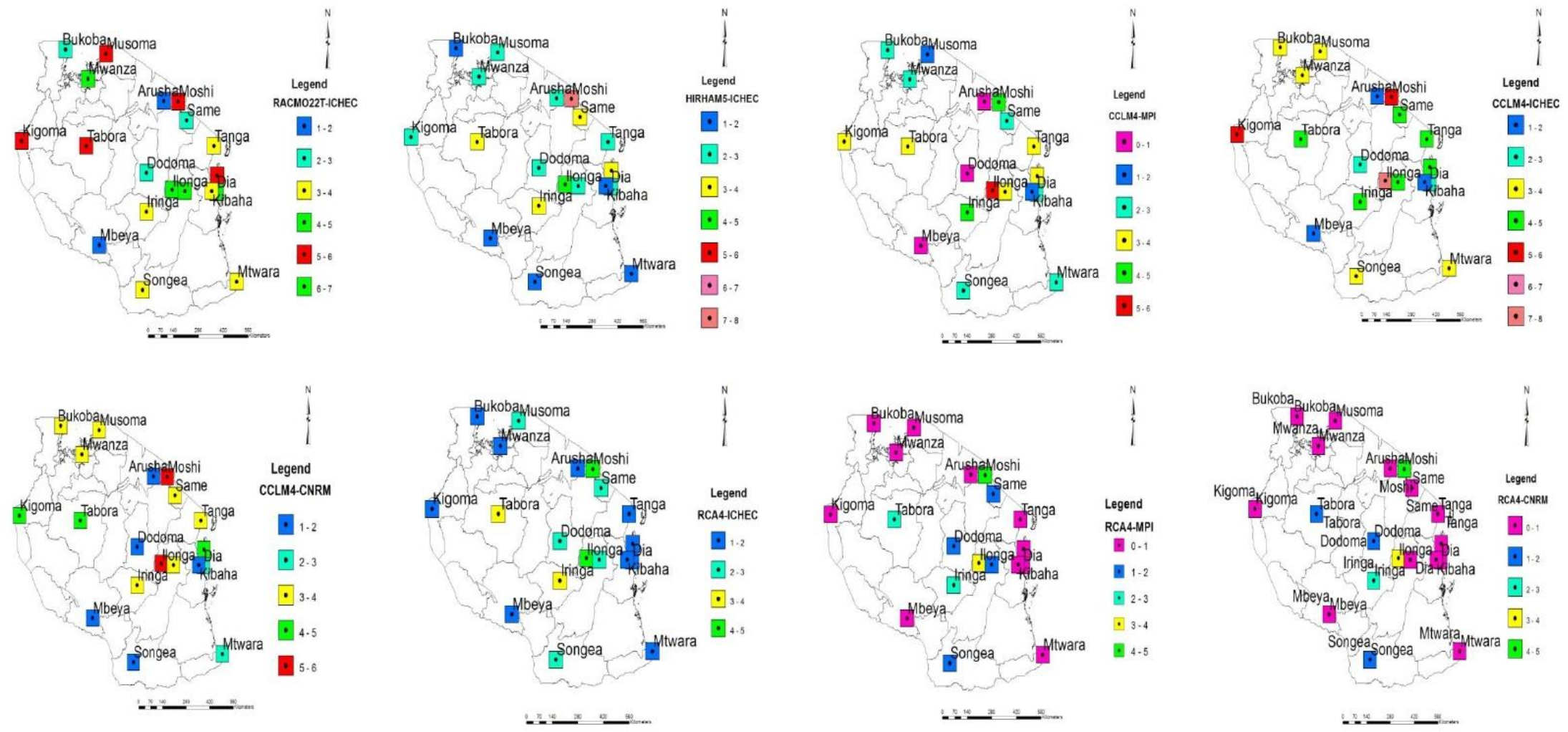

Figure 6 RMSE of RCMs $\left({ }^{\circ} \mathrm{C}\right)$ in simulating maximum temperature at different stations in Tanzania. 
Note that lower biases alone do not necessarily indicate the best model in simulating TN, TX and rainfall. One also needs to consider the RMSE: the best model may have smaller biases but should also have smaller RMSE. This is noticeable for instance with RCA4 driven by ICHEC simulating TN over Musoma and Mwanza regions with biases in the range of $-2{ }^{\circ} \mathrm{C}$ to zero. This indicates that RCA4 driven by ICHEC simulates TN for Musoma and Mwanza with similar level of performance. However, results from the RMSE indicate that the model simulates TN over Musoma and Mwanza with an error in the range of zero to $1{ }^{\circ} \mathrm{C}$ and 1 to $2{ }^{\circ} \mathrm{C}$ respectively.

The NRMSE of RCM rainfall simulations over different stations is presented in Figure 7. RACMO22T driven by ICHEC simulate rainfall over Southern, Northern and coastal regions with an error in the range of 31 to $46 \%$. HIRHAM5 driven by ICHEC simulate rainfall over Southern coast, Songea, central and Bukoba regions with an error in the range of 0 to 54\%. In general RACMO22T driven by ICHEC simulates rainfall over most stations better compared to other RCMs irrespective of the driving GCM.

Results from the Pearson's correlation coefficient for simulating annual cycles of TN, TX and rainfall are shown in Tables 3 and 4. From these tables, simulated TN, TX and rainfall by all RCMs compared well with observed TN, TX and rainfall over most stations. Simulated TN and TX from RACMO22T driven by ICHEC are negatively correlated with observed TN and TX over Bukoba, Musoma, Mwanza, Kigoma and Mtwara. These stations are placed close to mountains and water bodies. This may affect the performance of the models due to inability to represent complex dynamics processes from interaction of water bodies and orographies, including issues such as stable boundary layer processes, given that TN from all stations close to water bodies are weakly and negatively correlated with simulated TN. In general the RCMs simulate TN better than TX over most stations. The simulated rainfall by the RCMs is positively correlated with observed rainfall. It is important to mention here that the RCMs simulate TN and TX better than rainfall in most stations. Simulated rainfall correlate better with observed rainfall in the unimodal region than in the bimodal region. 

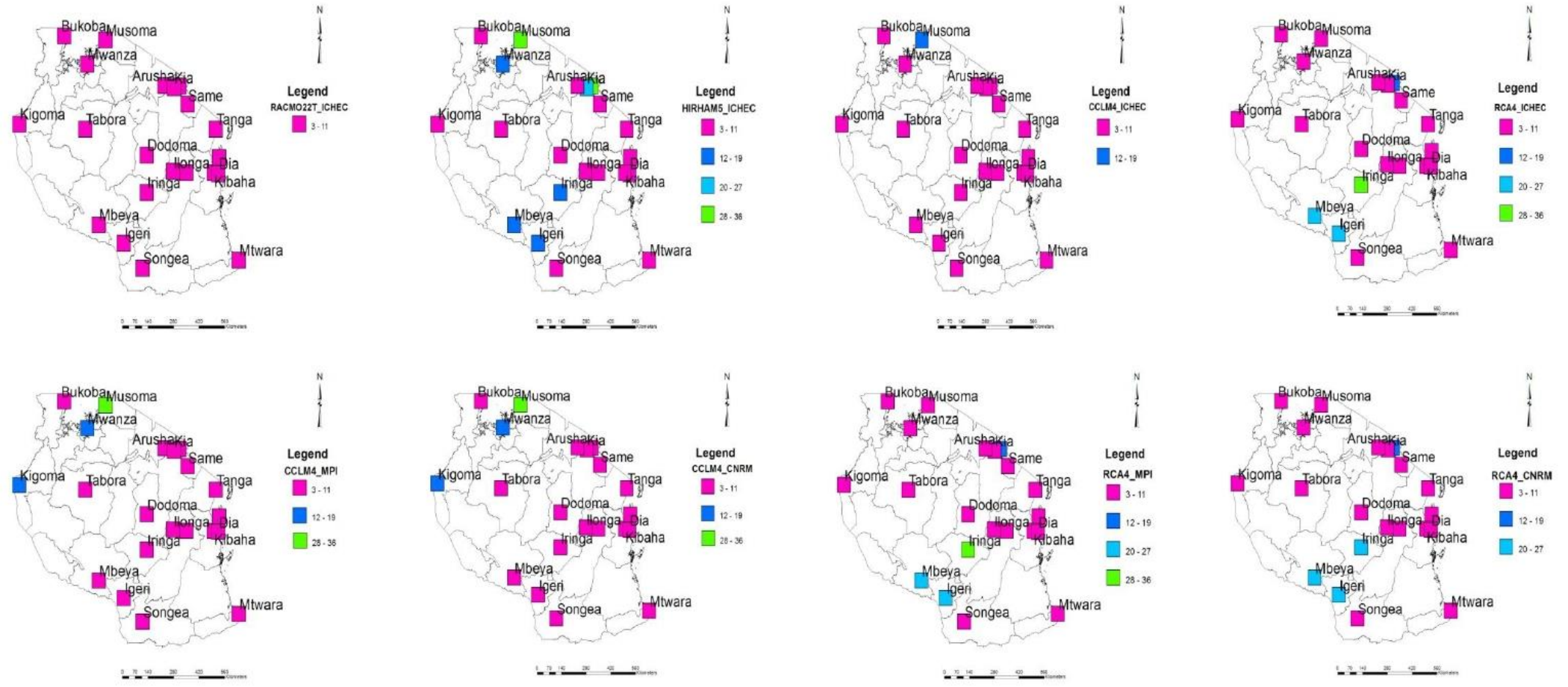

Figure 7 NRMSE (\%) of RCMs in simulating rainfall at different stations in Tanzania (note that the scales are different for each model). 


\begin{tabular}{|c|c|c|c|c|c|c|c|c|c|c|c|c|c|c|c|c|}
\hline \multirow{2}{*}{ Station } & \multicolumn{2}{|c|}{ RACMO22T-CHEC } & \multicolumn{2}{|c|}{ HIRHAM5-ICHEC } & \multicolumn{2}{|c|}{ CCLM-MPI } & \multicolumn{2}{|c|}{ CCLM-CNRM } & \multicolumn{2}{|c|}{ CCLM-ICHEC } & \multicolumn{2}{|c|}{$R C A 4-M P I$} & \multicolumn{2}{|c|}{ RCA4-ICHEC } & \multicolumn{2}{|c|}{ RCA4-CNRM } \\
\hline & $\mathrm{TN}$ & $\mathrm{TX}$ & $\mathrm{TN}$ & $\mathrm{TX}$ & $\mathrm{TN}$ & $\mathrm{TX}$ & $\mathrm{TN}$ & TX & $\mathrm{TN}$ & $\mathrm{TX}$ & $\mathrm{TN}$ & TX & $\mathrm{TN}$ & $\mathrm{TX}$ & $\mathrm{TN}$ & $\mathrm{TX}$ \\
\hline Arusha & 0.7 & 0.4 & 0.7 & 0.9 & 0.7 & 0.9 & 0.9 & 0.8 & 0.8 & 0.9 & 0.8 & 0.8 & 0.8 & 0.6 & 0.8 & 0.8 \\
\hline Bukoba & -0.8 & -0.5 & -0.6 & 0.1 & 0.7 & 0.7 & 0.8 & 0.7 & 0.7 & 0.5 & 0.8 & 0.5 & 0.6 & 0.3 & 0.8 & 0.5 \\
\hline Dia & 0.9 & 0.5 & 0.9 & 0.9 & 0.9 & 0.9 & 0.9 & 0.7 & 0.9 & 0.9 & 0.9 & 0.9 & 0.9 & 0.9 & 0.9 & 0.8 \\
\hline Morogoro & 0.9 & 0.3 & 0.9 & 0.9 & 0.9 & 0.9 & 0.9 & 0.7 & 0.9 & 0.9 & 0.9 & 0.9 & 0.9 & 0.9 & 0.9 & 0.8 \\
\hline Musoma & -0.3 & -0.1 & -0.5 & 0.3 & 0.8 & 0.6 & 0.9 & 0.8 & 0.8 & 0.5 & 0.8 & 0.6 & 0.7 & 0.3 & 0.8 & 0.6 \\
\hline Tanga & 0.9 & 0.9 & 0.9 & 0.9 & 0.9 & 0.9 & 0.9 & 0.9 & 0.9 & 0.9 & 0.9 & 0.9 & 0.9 & 0.9 & 0.9 & 0.9 \\
\hline Zanzibar & 0.8 & 0.8 & 0.9 & 0.8 & 0.8 & 0.6 & 0.8 & 0.4 & 0.8 & 0.8 & 0.9 & 0.9 & 0.9 & 0.9 & 0.8 & 0.8 \\
\hline Same & 0.9 & 0.4 & 0.9 & 0.9 & 0.9 & 0.9 & 0.9 & 0.7 & 0.9 & 0.9 & 0.9 & 0.9 & 0.8 & 0.8 & 0.9 & 0.8 \\
\hline Mwanza & -0.5 & 0.6 & -0.3 & 0.9 & 0.9 & 0.9 & 0.8 & 0.9 & 0.8 & 0.9 & 0.3 & 0.6 & 0.3 & 0.6 & 0.5 & 0.6 \\
\hline Moshi & 0.9 & 0.4 & 0.9 & 0.9 & 0.9 & 0.9 & 0.9 & 0.8 & 0.9 & 0.9 & 0.8 & 0.9 & 0.8 & 0.7 & 0.8 & 0.8 \\
\hline Ilonga & 0.9 & 0.4 & 0.9 & 0.9 & 0.9 & 0.9 & 0.9 & 0.8 & 0.9 & 0.9 & 0.9 & 0.9 & 0.9 & 0.8 & 0.9 & 0.8 \\
\hline Kibaha & 0.9 & 0.1 & 0.9 & 0.9 & 0.9 & 0.9 & 0.9 & 0.6 & 0.9 & 0.9 & 0.9 & 0.9 & 0.9 & 0.9 & 0.9 & 0.8 \\
\hline Dodoma & 0.8 & 0 & 0.9 & 0.9 & 0.9 & 0.9 & 0.9 & 0.8 & 0.9 & 0.8 & 0.9 & 0.7 & 0.9 & 0.4 & 0.9 & 0.5 \\
\hline Iringa & 0.9 & 0.5 & 0.9 & 0.9 & 0.9 & 0.9 & 0.9 & 0.8 & 0.9 & 0.9 & 0.9 & 0.7 & 0.9 & 0.6 & 0.9 & 0.4 \\
\hline Kigoma & -0.1 & 0.8 & -0.2 & 0.9 & 0.9 & -0.3 & 0.9 & 0.8 & 0.9 & 0.9 & 0.9 & 0.8 & 0.9 & 0.9 & 0.9 & 0.7 \\
\hline Mbeya & 0.9 & 0.6 & 0.9 & 0.9 & 0.9 & 0.9 & 0.9 & 0.9 & 0.9 & 0.9 & 0.9 & 0.8 & 0.9 & 0.8 & 0.9 & 0.7 \\
\hline Mtwara & 0.9 & -0.2 & 0.9 & 0.9 & 0.9 & 0.9 & 0.9 & 0.9 & 0.9 & 0.9 & 0.9 & 0.9 & 0.9 & 0.9 & 0.9 & 0.9 \\
\hline Songea & 0.9 & 0.5 & 0.9 & 0.9 & 0.9 & 0.9 & 0.9 & 0.9 & 0.9 & 0.8 & 0.9 & 0.9 & 0.9 & 0.8 & 0.9 & 0.8 \\
\hline Tabora & 0.5 & 0.6 & 0.9 & 0.9 & 0.9 & 0.9 & 0.9 & 0.9 & 0.9 & 0.9 & 0.7 & 0.7 & 0.5 & 0.6 & 0.7 & 0.4 \\
\hline Average & 0.6 & 0.4 & 0.6 & 0.8 & 0.9 & 0.8 & 0.9 & 0.8 & 0.9 & 0.8 & 0.8 & 0.8 & 0.8 & 0.7 & 0.8 & 0.7 \\
\hline
\end{tabular}

Table 3 Pearson correlation coefficient between observed and simulated annual cycles of minimum and maximum temperature. 


\begin{tabular}{|c|c|c|c|c|c|c|c|c|}
\hline Station & $\begin{array}{l}\text { RACMO22T- } \\
\text { ICHEC }\end{array}$ & $\begin{array}{l}\text { HIRHAM5- } \\
\text { ICHEC }\end{array}$ & $\begin{array}{l}C C L M- \\
M P I\end{array}$ & $\begin{array}{l}\text { CCLM- } \\
\text { CNRM }\end{array}$ & $\begin{array}{l}\text { CCLM- } \\
\text { ICHEC }\end{array}$ & $\begin{array}{l}\text { RCA4- } \\
\text { MPI }\end{array}$ & $\begin{array}{l}\text { RCA4- } \\
\text { ICHEC }\end{array}$ & $\begin{array}{l}\text { RCA4- } \\
\text { CNRM }\end{array}$ \\
\hline Arusha & 0.53 & 0.55 & 0.48 & 0.71 & 0.42 & 0.66 & 0.39 & 0.69 \\
\hline Bukoba & 0.59 & 0.84 & 0.42 & 0.63 & 0.49 & 0.66 & 0.66 & 0.57 \\
\hline Dia & 0.87 & 0.80 & 0.74 & 0.41 & 0.85 & 0.80 & 0.88 & 0.43 \\
\hline Morogoro & 0.76 & 0.84 & 0.66 & 0.35 & 0.71 & 0.67 & 0.74 & 0.56 \\
\hline Musoma & 0.40 & 0.44 & 0.42 & 0.66 & 0.38 & 0.76 & 0.47 & 0.65 \\
\hline Tanga & 0.82 & 0.55 & 0.69 & 0.36 & 0.65 & 0.68 & 0.65 & 0.42 \\
\hline Zanzibar & 0.95 & 0.76 & 0.79 & 0.44 & 0.86 & 0.85 & 0.89 & 0.44 \\
\hline Same & 0.62 & 0.43 & 0.79 & 0.40 & 0.67 & 0.68 & 0.61 & 0.61 \\
\hline Mwanza & 0.42 & 0.87 & 0.64 & 0.72 & 0.68 & 0.70 & 0.51 & 0.67 \\
\hline Moshi & 0.27 & 0.24 & 0.35 & 0.35 & 0.22 & 0.51 & 0.45 & 0.55 \\
\hline Ilonga & 0.82 & 0.74 & 0.74 & 0.54 & 0.77 & 0.74 & 0.71 & 0.58 \\
\hline Kibaha & 0.84 & 0.84 & 0.66 & 0.35 & 0.78 & 0.73 & 0.84 & 0.45 \\
\hline Kia & 0.41 & 0.41 & 0.47 & 0.48 & 0.36 & 0.54 & 0.44 & 0.55 \\
\hline Mlingano & 0.42 & 0.20 & 0.58 & 0.56 & 0.55 & 0.47 & 0.65 & 0.49 \\
\hline Dodoma & 0.91 & 0.95 & 0.92 & 0.87 & 0.91 & 0.78 & 0.70 & 0.54 \\
\hline Iringa & 0.94 & 0.95 & 0.93 & 0.84 & 0.93 & 0.82 & 0.82 & 0.67 \\
\hline Kigoma & 0.87 & 0.87 & 0.83 & 0.96 & 0.83 & 0.92 & 0.87 & 0.84 \\
\hline Mbeya & 0.93 & 0.96 & 0.95 & 0.89 & 0.93 & 0.89 & 0.90 & 0.80 \\
\hline Mtwara & 0.93 & 0.96 & 0.75 & 0.55 & 0.93 & 0.71 & 0.68 & 0.65 \\
\hline Songea & 0.96 & 0.96 & 0.97 & 0.95 & 0.95 & 0.88 & 0.91 & 0.82 \\
\hline Tabora & 0.87 & 0.93 & 0.89 & 0.92 & 0.88 & 0.86 & 0.79 & 0.76 \\
\hline Igeri & 0.92 & 0.89 & 0.93 & 0.90 & 0.88 & 0.92 & 0.91 & 0.87 \\
\hline Average & 0.73 & 0.73 & 0.71 & 0.63 & 0.71 & 0.74 & 0.70 & 0.62 \\
\hline
\end{tabular}

Table $4 \quad$ Pearson correlation coefficient between observed and simulated annual cycles of rainfall.

\subsection{Annual cycle of rainfall and temperatures}

The performance of RCMs in simulating the annual cycle of TN and TX for Tanzania as a whole is presented in Figure 8. Before comparison, the values of observed TN and TX from 22 stations are averaged to get a single time series of TN and TX to compare with RCMs outputs (which are calculated in the same way). It is found that overall the RCMs capture the timing of the annual cycles of TN and TX, although they do not in general reproduce the magnitude of TN and TX. HIRHAM5 driven by ICHEC and CCLM4 driven by MPI and CNRM overestimate TN throughout the annual cycle. RACMO22T driven by ICHEC, and RCA4 driven by ICHEC and CNRM underestimate TN. The RCMs, including the ensem- 
ble average, all systematically underestimate TX throughout the year. Therefore, it can be concluded that CORDEX RCMs reproduce the timing of the annual cycle in TN and TX, but underestimate TX climatology. RCA4 driven by all three GCMs reproduce the magnitude of observed TN and TX better than other models.

The performance of RCMs in simulating the annual cycle of rainfall over bimodal and unimodal regions of Tanzania is presented in Figure 9. Before comparison the values of observed rainfall from the 14 stations in the bimodal area and the 8 stations in the unimodal are averaged to get a single time series of observed rainfall to compare with the RCMs output. Over the bimodal region (see Figure 9a) the observed data exhibit two peaks of rainfall, a primary maximum is in April, a secondary one is in November and a low (minimum) in June, July and August. The RCMs systematically underestimate rainfall amount particularly in the MAM season and overestimate the rainfall amount in the OND season. In the unimodal region (see Figure 9b) the length of the rainy season extends from September to May having its peak in the month of January. Further, the models, including the ensemble, average overestimate the rainfall amount from September to January.

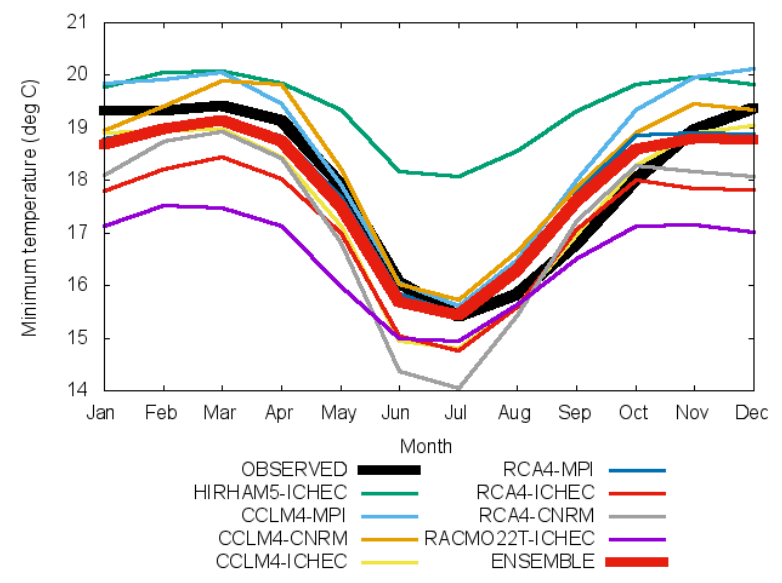

(a)

\section{TN}

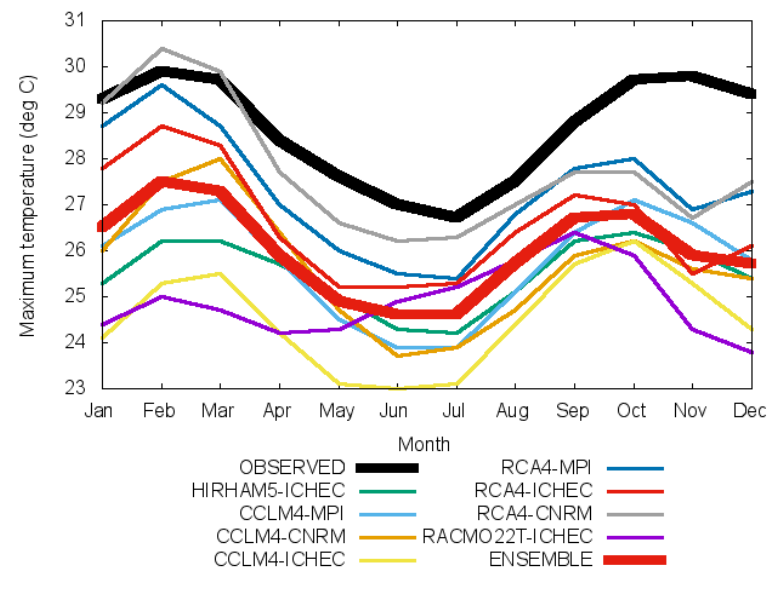

(b) TX

Figure $8 \quad$ Observed and simulated monthly TN and TX over Tanzania (calculated from1971-2005).

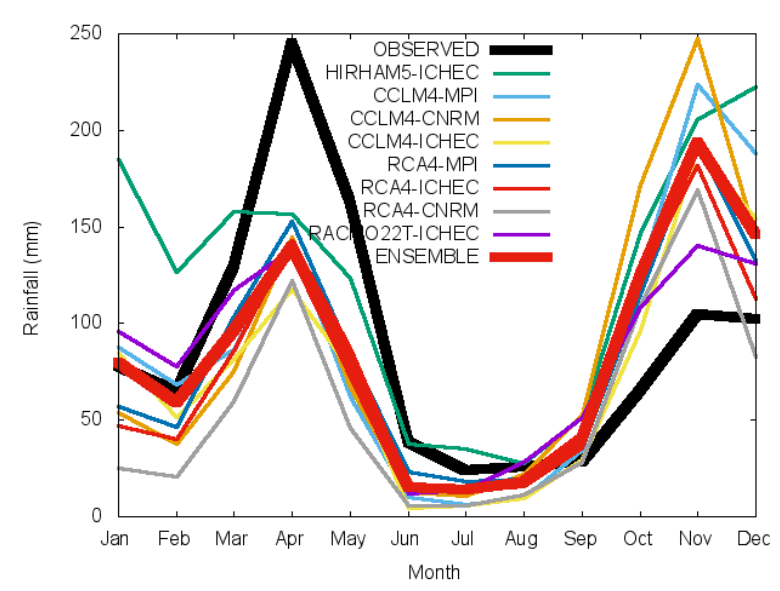

(a) bimodal region

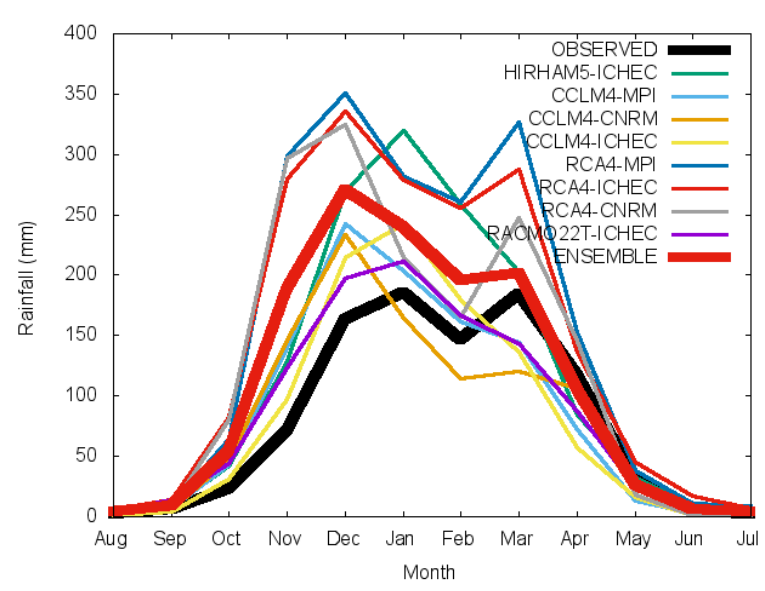

(b) unimodal region

Figure 9 Observed and simulated monthly mean rainfall in bimodal and unimodal regions (calculated from 19712005). 


\subsection{Interannual variability of TN, TX and rainfall}

Outputs from CORDEX RCMs driven by ERA-Interim data are used to assess the ability of the RCMs to simulate interannual variations of TN, TX and rainfall. These data are available for the period of 1989-2008. The performance of the models in simulating interannual variability in TN and TX is presented in Figure 10a, b. This figure shows that all RCMs captured the pattern of interannual variability in TN and TX well. The magnitude of TN is overestimated by all RCMs. All RCMs including the ensemble average underestimate the magnitude of TX.

The performance of CORDEX RCMs in simulating interannual variability of rainfall is analysed by comparing simulated and observed interannual variations in rainfall in bimodal and unimodal regions (see Figure 11a, b). All RCMs except HIRHAM5 reproduce the interannual variability of rainfall in unimodal regions. Furthermore, all RCMs except RCA4 reproduce the interannual variability of rainfall in bimodal regions. It can be concluded that CORDEX RCMs driven by ERA-Interim data fairly capture the interannual variability of rainfall in unimodal and bimodal regions.

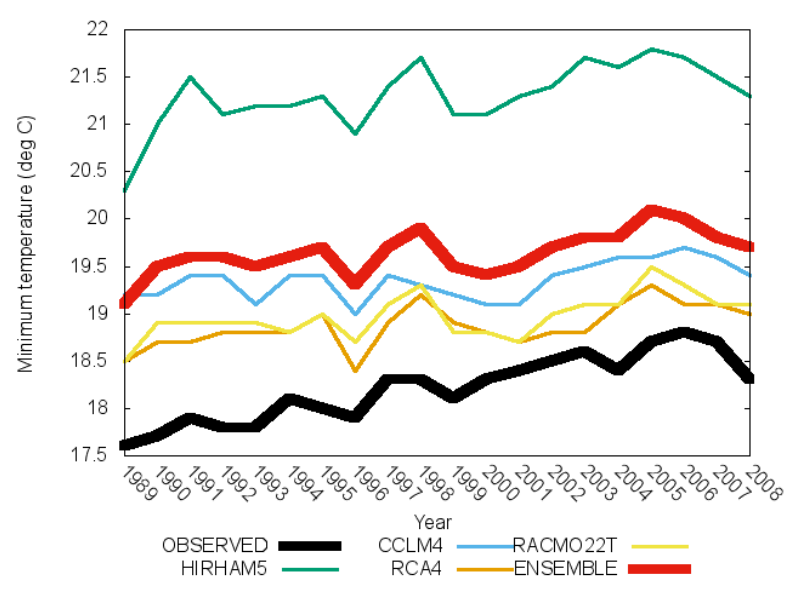

(a) $\mathrm{TN}$

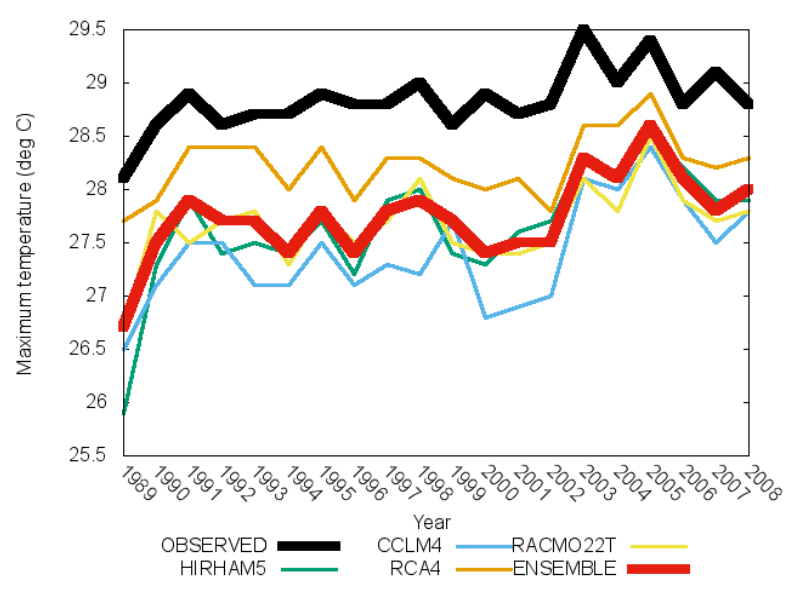

(b) TX

Figure 10 Annual average observed and simulated TN and TX of Tanzania.

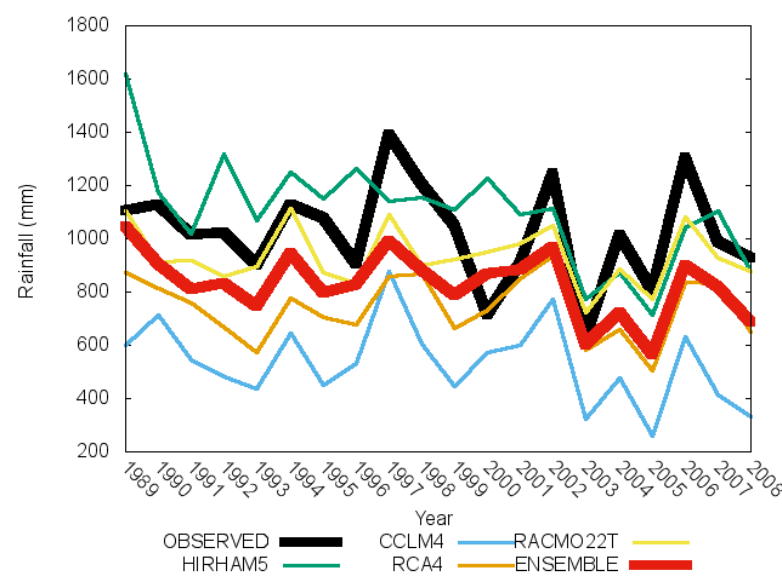

(a) bimodal region

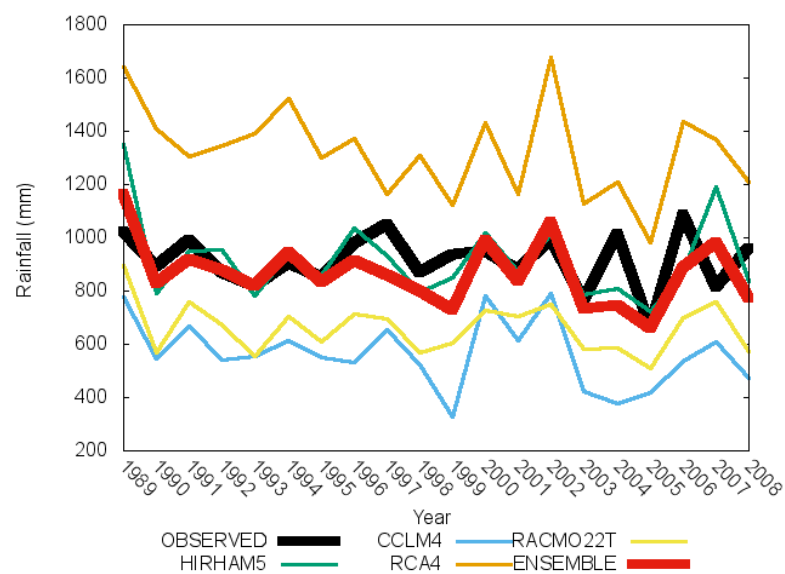

(b) unimodal region

Figure 11 Annual average observed and simulated rainfall in the bimodal and unimodal regions. 


\subsection{Trends in observed and simulated temperatures and rainfall}

The performance of the models requires further examination, particularly in their ability to reproduce trends in TN, TX and rainfall. However, the analysis of rainfall trends indicated decreasing trends that are non-statistically significant and therefore cannot be used to judge model performance.

The performance of the RCMs in simulating trends in TN and TX for Tanzania is presented in Table 5. Observed data indicate increasing trends in TN and TX at the 95\% significance level. All RCMs captured the increasing trends in TN and TX. All RCMs captured the statistically significant increasing trend in TN, although the trend in the models is only around a third to a half that in the observations. Therefore these results suggest the potential use of the CORDEX RCMs in simulating TN change over Tanzania. The RCMs ability to simulate trends and gradient at different weather stations in Tanzania is shown in the table. It is important to note that, contrary to the observations, the models generally indicate stronger increasing trends in TX than TN, except for one model (RCA4). Furthermore one model (HIRHAM5) indicates statistically increasing trend in TX which is nearly 3 times the observed rate.

\begin{tabular}{lll}
\hline Regional climate model & $\begin{array}{l}\text { Minimum temperature } \\
\left({ }^{\circ} \text { C/year }\right)\end{array}$ & $\begin{array}{l}\text { Maximum temperature } \\
\left({ }^{\circ} \text { C/year }\right)\end{array}$ \\
\hline RACMO22T & $0.022(*)$ & $0.023()$. \\
HIRHAM5 & $0.037(* *)$ & $0.053(* *)$ \\
CCLM4 & $0.020(*)$ & $0.041(*)$ \\
RCA4 & $0.022(* *)$ & $0.017()$. \\
ENSEMBLE & $0.026(* *)$ & $0.032(*)$ \\
OBSERVED & $0.060(* * *)$ & $0.019(*)$ \\
\hline
\end{tabular}

Table 5 The Mann-Kendall trend and Theil-SEN's slope estimate in simulated and observed minimum temperature (all RCMs are driven by ERA-Interim reanalysis data). (***): trend significant at $\alpha=0.001 ;(* *)$ : trend significant at $\alpha=0.01 ;(*)$ : trend significant at $\alpha=0.05$; and (.): trend not significant.

\section{Conclusions}

In this study, four CORDEX regional climate models (RCMs) driven by three GCMs (MPI, ICHEC and CNRM) and ERA-Interim data are analysed for their ability to simulate historical or recent climate conditions of Tanzania. The analysis is based on determining how well the RCMs reproduce climatological trends, and interannual and annual cycles of TN, TX and rainfall. Statistical measures of model performance that include the bias, root mean square error, correlation and trend analysis are used. Results showed that all RCMs captured the annual cycle of TN, TX and rainfall, however, generally fail to reproduce the magnitude of rainfall in the March-April-May (MAM) and October-November-December (OND) seasons. Furthermore, most of the RCMs reasonably reproduce interannual variations and trends in TN and TX. Although RCA4 is slightly better than other RCMs in simulating TN and TX over different stations in Tanzania, all models show reasonably comparable errors. RACMO22T driven by ICHEC simulates rainfall over most stations better than other RCMs irrespective of the driving GCM.

The sources of the uncertainties for RCMs in simulating climate variables at different stations can be compared. These uncertainties come from both RCMs and the driving GCMs. RACMO22T and HIRHAM5 both driven by ICHEC GCM simulate TN, TX and rainfall with different level of performance over all stations, suggesting this difference is mainly due to RACMO22T and HIRHAM5 formulations. The uncertainties that arise from driving GCMs are analysed when the same RCM driven by different GCMs simulate TN, TX and rainfall differently over most stations. For example, CCLM4 driven by three GCMs (MPI, ICHEC and CNRM), simulate TN differently over most stations. In general, the biases and the RMSE arising from the RCMs and driving GCMs in simulating TN and TX are not too large in most stations. The RCMs simulate TN better than TX in most stations, with TX underestimated almost everywhere. Although simulated rainfall over 
unimodal compares with observed rainfall with high correlation coefficients, analysis from NBias and NRMSE indicate the models simulate rainfall better over bimodal regions than over unimodal region.

The results presented in this study are useful, first to climate modellers, since the results may help them to try to investigate why one model can well simulate one climate parameter and poorly simulate other climate parameters. The results may also be useful to studies that require weather variables at specific location, for example studies that evaluate the impact of climate change on the agriculture sector, or require specific location climate information. Therefore one can choose specific RCMs that well reproduce the climate of the location of interest.

\section{Acknowledgments}

Authors are grateful to the Tanzania Meteorological Agency for provision of observed meteorological data, and for CORDEX Africa for providing model data used in this study.

\section{References}

Agrawala, S.A., Moehder, A., Hemp, M., Van Aalst, S.J., Hitz, H.M.S., Meena, T., Hyera, T. and Mwaipopo, O. 2003. Development and Climate Change in Tanzania: Focus on Mount Kilimanjaro. OECD, Paris.

Ahmad, I., Tang, D., Wang, T.F., Wang, M. and Wagan, B. 2015. Precipitation trends over time using Mann-Kendall and Spearman's rho tests in Swat River Basin, Pakistan, Advances in Meteorology, 2015, Article ID 431860, 15 pp. doi: $10.1155 / 2015 / 431860$

Ahmed, S.A., Diffenbaugh, N., Hertel, T.W., Lobell, D.B., Ramankutty, N., Rios, A.R. and Rowhani, P. 2011. Climate volatility and poverty vulnerability in Tanzania. Global Environmental Change, 21(1): 46-55. doi:10.1016/j.gloenvcha.2010.10.003

Anyah, R.O. and Semazzi, H.H.M. 2007. Variability of East African rainfall based on multi year RegCM3 simulations. Int J Climatol, 27, 357-371.

Arndt, C., Farmer, W., Strzepek, K. and Thurlow, J. 2011. Climate change, agriculture, and food security in Tanzania, United Nations University, UNU-WIDER.

Auffhammer, M., Hsiang, S.M., Schlenker, W. and Sobel, A. 2013. Using weather data and climate model output in economic analyses of climate change, Review of Environmental Economics and Policy, 7(2), 181-198. doi:10.1093/reep/ret016

Black, E. 2005. The relationship between Indian Ocean sea-surface temperature and East African rainfall. Philos Trans $R$ Soc, 363, 43-47. doi: 10.1098/rsta.2004.1474

Black, E., Slingo, J., and Sperber, K.R. 2003. An observational study of the relationship between excessively strong short rains in coastal east Africa and Indian ocean SST. Mon Weather Rev, 131, 74-94.

Daniels, A.E., Morrison, J.F., Joyce, L.A., Crookston, N.L., Chen, S.C., and McNulty, S.G. 2012. Climate projections FAQ. Gen. Tech. Rep. RMRS-GTR-277WWW. Fort Collins, CO: U.S. Department of Agriculture, Forest Service, Rocky Mountain Research Station, $32 \mathrm{pp}$.

Dell, M., Jones, F.B. and Olken, B.A. 2014. What do we learn from the weather? The new climate-economy literature. Journal of Economic Literature, 52(3), 740-798. http://dx.doi:org/10.1257/jel.52.3.740

Denis, B., Laprise, R., Caya, D. and Co^te, J. 2002. Downscaling ability of one-way nested regional climate models: the Big-Brother Experiment, Climate Dynamics, 18, 627-646. doi:10.1007/s00382-001-0201-0

Ehrhart, C., and Twena, M. 2006. Climate change and poverty in Tanzania: realities and response options for CARE. Background report. CARE International Poverty-Climate Change Initiative. Available at: http://www.care.dk/multimedia/pdf/web_english/Climate\%20Change\%20and\%20Poverty\%20in\%20Tanzania\%20$\% 20$ Country\%20Profile.pdf

Endris, H.S., Omondi, P., Jain, S., Lennard, C., Hewitson, B., Chang'a, L., Awange, J.L., Dosio, A., Ketiem, P., Nikulin, G., Panitz, H.J., Büchner, M., Stordal, F. and Tazalika, L. 2013. Assessment of the Performance of CORDEX regional climate models in simulating east African rainfall. J. Climate, $26, \quad 8453-8475$. http://www.taccire.suanet.ac.tz/xmlui/bitstream/handle/123456789/472/Climate\%20change\%20and\%20poverty\%20200 6.pdf? sequence $=1$

Enfors, E. and Gordon, L. 2008. Dealing with drought: The challenge of using water system technologies to break dryland poverty traps. Global Environmental Change, 18, 607-616. doi:10.1016/j.gloenvcha.2008.07.006 
Engelbrecht, F.A., Mcgregor, J.L. and Engelbrecht, C.J. 2009. Dynamics of the conformal-cubic atmospheric model projected climate-change signal over southern Africa. Int. J. Climatol., 29, 1013-1033. doi: 10/1002/joc.1742.29

Flato, G., Marotzke, J., Abiodun, B., Braconnot, P., Chou, S.C., Collins, W., Cox, P., Driouech, F., Emori, S., Eyring, V., Forest, C., Gleckler, P., Guilyardi, E. , Jakob, C., Kattsov, V., Reason, C. and Rummukainen, M. 2013. evaluation of climate models. In Stocker, T.F., D. Qin, G.-K. Plattner, M. Tignor, S.K., Allen, J., Boschung, A., Nauels, Y. Xia, V. Bex and P.M. Midgley (eds.): Climate Change 2013: The Physical Science Basis. Contribution of Working Group I to the Fifth Assessment Report of the Intergovernmental Panel on Climate Change. Cambridge University Press, Cambridge, United Kingdom and New York, NY, USA.

Gordon, N. and Shaykewich, J. 2000. Guidelines on performance assessment of public weather services. WMO/TD No. $1023,32 \mathrm{pp}$.

Hartkamp, A.D., De Beurs, K., Stein, A. and White, J.W. 1999. Interpolation techniques for climate variables. NRG-GIS Series 99-01. Mexico, D.F.: CIMMYT.

Hassan, Z., Shamsudin, S., Harun, S. 2013. Application of SDSM and LARS-WG for simulating and downscaling of rainfall and temperature, Theor Appl Climatol, 116, 43-257. doi: 10.1007/s00704-013-0951-8

Hofstra, N., Haylock, M., New, M. and Jones, P.D. 2009. Testing E-OBS European high-resolution gridded dataset of daily precipitation and surface temperature, J. Geophys. Res., 114, D21101, doi:10.1029/2009JD011799.

Ingole, P.V., and Nichat, M.K. 2013. Landmark based shortest path detection by using Dijkestra Algorithm and Haversine Formula, International Journal of Engineering Research and Applications, 3, 162-165.

IPCC. 2007. Working Group II Fourth Assessment Report. Climate Change: Climate Change Impacts, Adaptation and Vulnerability. Available at: http://www.ipcc.ch/SPM6avr07.pdf

Køltzow, M.A.O., Iversen, T. and Haugen, J.E. 2011. The importance of lateral boundaries, surface forcing and choice of domain size for dynamical downscaling of global climate simulations, Atmosphere, 2, 67-95. doi:10.3390/atmos2020067

Ly, S., Charles, C. and Degre, A. 2013. Geostatistical interpolation of daily rainfall at catchment scale: the use of several variogram models in the Ourthe and Ambleve catchments, Belgium, Hydrol. Earth Syst. Sci., 15, 2259-2274. www.hydrol-earth-syst-sci.net/15/2259/2011/doi:10.5194/hess-15-2259-2011

Meier, H.E.M., Höglund, A., Döscher, R., Andersson, H., Löptien, U. and Kjellström, E. 2011. Quality assessment of atmospheric surface fields over the Baltic Sea from an ensemble of regional climate model simulations with respect to ocean dynamics, Oceanologia, 53(1-TI), 193-227.

Min, E., Hazeleger, W., Oldenborgh, G.J. and Sterl, A. 2013. Evaluation of trends in high temperature extremes in northwestern Europe in regional climate models, Environ. Res. Lett., 8. doi:10.1088/1748-9326/8/1/014011.

Müller, C., Cramer, W., Hare, W.L. and Lotze-Campen, H. 2011. Climate change risks for African agriculture. Proceedings of the National Academy of Sciences of the United States of America (PNAS) 108, 11, 4313-4315, www.pnas.org/cgi/doi/10.1073/pnas

Mwandosya, M.J., Nyenzi, B.S. and Luhanga, M.L. 1998. The assessment of vulnerability and adaptation to climate change impacts in Tanzania. Centre for Energy, Environment, Science and Technology (CEEST) Dar-es-Salaam, Tanzania.

Roux, B. 2009. Ultra high-resolution climate simulations over the Stellenbosch wine-producing region using a variableresolution model. M.Sc. Thesis. University of Pretoria, Pretoria, South Africa. 96 pp.

Shongwe, M.E., Lennard, C., Liebmann, B., Kalognomou, E.-A., Ntsangwane, L. and Pinto, I. 2015, An evaluation of CORDEX regional climate models in simulating precipitation over Southern Africa. Atmosph. Sci. Lett., 16, 199-207. doi: $10.1002 /$ asl2.538

Thornton, P.K., Jones, P.G., Alagarswamy, G. and Andresen, J. 2010. Spatial variation of crop yield response to climate change in East Africa. Glob Environ Change, 19, 54-65. doi: 10.1016/j.gloenvcha.2008.08.005

Thornton, P.K., Jones, P.G., Owiyo, T., Kruska, R.L., Herrero, M., Orindi, V., Bhadwal, S., Kristjanson, P., Notenbaert, A., Bekele, N., and Omolo, A. 2009. Climate change and poverty in Africa: mapping hotspots of vulnerability. African Journal of Agricultural and Resource Economics, 2(1), 24-44, Available at: http://hdl.handle.net/10568/663

Timiza, W. 2011. Climate variability and satellite - observed vegetation responses in Tanzania. Master thesis Physical Geography and Ecosystem Analysis, Lund University, Seminar series 205, 30 ECTS.

Villegas, J.R., and Jarvis, A. 2010. Downscaling global circulation model outputs: the delta method. Decision and Policy Analysis Working Paper No. 1, Centro internacional de agricultura Tropical.

Wilby, L.R., and Fowler, J.H. 2011. regional climate downscaling. Available at: http://www.pages-perso-juliecarreau.univ-montp2.fr/UM2/Packages_and_Tutorial_files/downscaling.pdf

Xiaoduo, P., Xin, L., Xiaokang, S., Xujun, H., Lihui, L., Liangxu, W. 2012. Dynamic downscaling of near-surface air temperature at the basin scale using WRF. Aacase study in the Heihe River Basin, China, Front. Earth Sci., 6(3), 314323. doi: 10.1007/s11707-012-0306-2. 